\title{
Isolation and identification of some uncommon bacterial species isolated from different clinical sample
}

\author{
Rahman K. Faraj ${ }^{1}$ and Muhamed N. Maarof $^{2}$ \\ ${ }^{1}$ Kalar general hospital $/ 2$ College of education for pure science-Tikrit university
}

\begin{abstract}
There are many opportunistic bacterial species that are uncommon and infrequently exist in clinical specimen, most of them are difficult to routine identification, even some of them are poorly documented in clinical specimen. also had no less role in the coordinates of the disease than common bacterial species. Six hundred and fifty samples were collected from patients attending to some hospitals in Sulaimanya City and Kalar General Hospital during the period from October 2015 to November 2016.

Samples were firstly cultured on different media in order to isolate and identify bacterial isolates according to cultural characteristics, morphological features and biochemical reactions in addition to Vitek 2 system for identifying uncommon and infrequent isolates. The identification and susceptibility test were performed in Kalar General Hospital. Isolated 286(44\%) bacterial strains from different clinical samples, 125 of them were identified by Vitek 2 automated system, while $23(8 \%)$ of isolates were considered as uncommon bacterial species.

The antimicrobial susceptibility of uncommon isolates, showed significant variation against twenty four antibiotics. Four isolates; Acinatobacter baumanii, Acinatobacter calcoaceticus, Enterobacter ludwigii and Gemella sanguinis were resistant to all antibiotics. Whereas Aerococcus urinae, (Citrobacter freundii and Alloiococcus otitis), (Morganella morganii, Sphingomonas paucimobilis, Pantoea agglomerans, Streptococcus sobrinus and Kocuria rosea n.2), ( Ochrobactrum anthropi n.1 and Kocura kristinae), (Ochrobactrum anthropi n.2 and Kocuria rosea n.1 ), (Pseudomonas stutzeri, Pseudomonas fluorescens and Citrobacter koseri ), (Aeromonas salmonicida and Micrococcus luteus n.1) and Micrococcus luteus (n.2) resistant to the antibiotics as these percentages $95.8 \%, 91.6 \%, 87.5 \%, 83.3 \%, 79.1 \%, 70.8 \%, 66.6 \%$ and $62.5 \%$, respectively.
\end{abstract}




\section{Introduction}

Coagulase negative staphylococci are the most common microorganisms isolated from clinical specimen, however, $85 \%$ of the isolates are contaminants, usually from skin contamination at the time of collection (Weinstein et al., 1997), also Escherichia coli (Bodey et al., 1986), Klebsiella pneumoniae (Bodey et al., 1989), Pseudomonas aeruginosa (Bodey and Jadeja 1985), Staphylococcus aureus, Streptococcus pneumoniae (Folland et al., 1974) considered as the most common bacterial species pathogens from human clinical sites. Citrobacter species is the best example of these bacterial species that are infrequent nosocomial pathogens and difficult in routine identification, usually utilize citrate as a sole carbon source. In addition to Citrobacter spp. there are some bacterial species that are uncommon or infrequently exist in clinical sample such as Acinatobacter calcoaceticus(Pal and Kale 1981), Pseudomonas stutzeri (Robert and Overman 1994), Pseudomonas fluorescens (Guttman 2008), Sphingomonas paucimobilis (Bhatia and Tomar 2016), Kocuria kristinae (Tewari et al., 2013 and Chen et al., 2015), Gemella sanguinis (Ma et al., 2015).

The identification by Vitek 2 system within 3 hours using fluorescence reading, the weakness of this system was the breadth of its identification database, especially for Citrobacter spp., Enterobacter spp., Pantoea spp., nonfermenting bacilli, such as Pseudomonas spp. and Acinetobacter, and for gram-positive cocci, such as Streptococcaceae (Jossart and Courcol 1999). Here we aims in this study; isolation and identification of some species of opportunistic bacteria that are uncommon and difficult to investigation in routine laboratory method, in addition to determine resistance of their uncommon isolates during antibiotic susceptibility.

\section{Materials and methods}

\section{Specimen collection}

Six hundred and fifty samples were collected from different clinical specimens including 496 urine, 71 stool, 34 blood, 33 wound, 16 sputum from Kalar General Hospital and some hospital Lab. in Sulaimanya City, during the periods from October 2015 to November 2017.

\section{Isolation of bacterial species}

Patients samples were transferred to the laboratory, then inoculated onto blood, MacConkey and mannitol salt agar by streaking method and incubated at $37^{\circ} \mathrm{C}$ for $18-24$ hours(if no growth on plates reincubated for 48 hours); single colonies that produce pigment or any characteristic 
were transferred to nutrient agar and subcultured more than one time to obtain pure cultures( Levinsion 2010).

\section{Maintenance and storage of isolates}

To preserve the diagnosed bacterial isolates, without losing their genetic characteristics, nutrient agar plate was streaked with a single colony of bacteria, after 24 hours appearance of growth at $37^{\circ} \mathrm{C}$, one $\mathrm{ml}$ of nutrient broth was added to the surface of each plate and the growth harvested, then transferred to small vials containing nutrient broth with sterilized $1 \mathrm{ml}$ of $20 \%$ glycerol, then stored at $-20^{\circ} \mathrm{C}$ for several months as long term stock culture. Also nutrient agar slants were stored during the work in refrigerator as worked stock culture for less than a month (Ausubel et al., 1987).

\section{Identification of bacterial species}

Microscopic examination of stained bacteria by gram stain was done, which is one of the initial step towards a presumptive identification, also oxidase, catalase test and cultural characteristics on selective media were used as presumptive identification.

In addition to routine identification, we used Vitek 2 automated system; A bacterial suspension was made by sterile saline and made only one dilution for each test as simplicity, reading the barcode as traceability before introducing the bacterial suspension into the cassette, after 70 second introducing the cassette into the sealer chamber ( the sealing card and introduction into the reader-incubater was done by automated system). Automated injection of the cards regards the end of analysis cited by manufacture company (Biomerieux).

\section{Antibiotic susceptibility test}

It was done by disc diffusion method, eight discs spaced evenly, approximately $15 \mathrm{~mm}$ from the edge of the plate, and one disc placed in the center of the plate. Each disc was gently pressed down to ensure even contact with the medium. The plates were incubated at $37^{\circ} \mathrm{C}$ overnight. The size of inhibition zone was measured by ruler on the under surface of the plate without opening the lid using the method described by Kirby-Bauer cited by(Vandepitte et al., 2003), and the result was compared with the standard diameter of inhibition zones for each antibiotic according to (CLSI). The twenty four antibiotic discs used in this research were Meropenem, Dorepenm, Azteronam, Penciilin G, Pipracillin, Ampicillin, Amoxiclave, Cefotacxime, 
Ceftriaxon, Cefazolin, Cephalothin, Cefadroxil, Cefexime, Cefepem, Ceftazidime, Ciprofloxacin, Levofloxacin, Amikacin, Netilmicin, Tobramycin, Nitrofurantion, Doxicycline, Tetracycline and Trimethoprime.

\section{Result and discussion}

From more than 650 clinical sample in different hospitals in Sulaimanya and Kalar city during the period from October 2015 to November 2016. Out of 286(44\%) bacterial strains were isolated, 125 of them were identified by Vitek 2 system. About 260(90\%) of isolates were common bacterial species and $23(9.8 \%)$ of isolates were considered as uncommon bacterial species, whereas $3(1 \%)$ of isolates were not identified by Viteck 2 system as shown in table(1) and table(2).

Table(1): number of uncommon bacteria isolates.

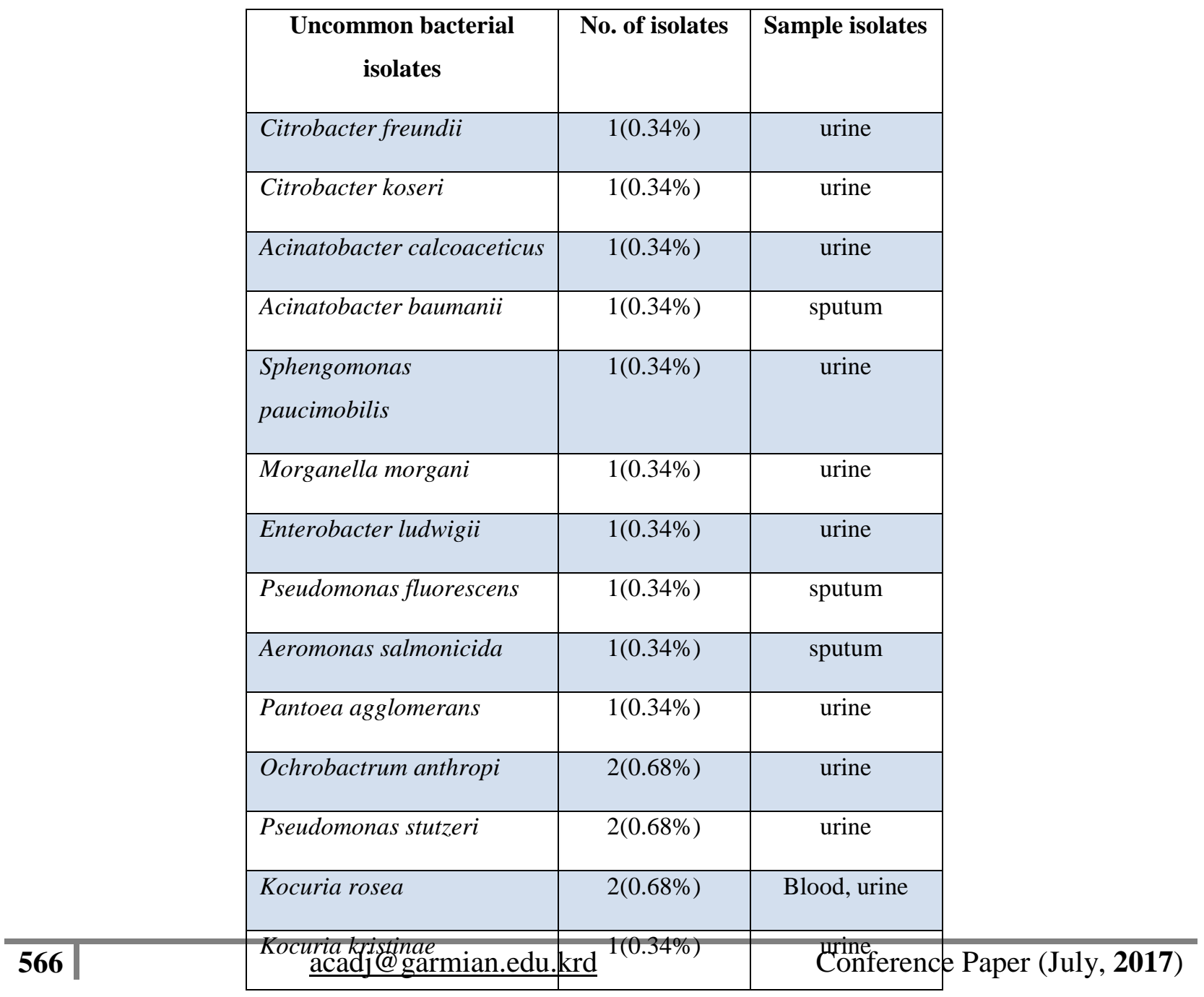




\begin{tabular}{|l|c|c|}
\hline Micrcoccus luteus & $2(0.68 \%)$ & urine \\
\hline Aerococcus urinae & $1(0.34 \%)$ & urine \\
\hline Alloiococcus otitis & $1(0.34 \%)$ & urine \\
\hline Gemella sanguinis & $1(0.34 \%)$ & urine \\
\hline Streptococcus sobrinus & $1(0.34 \%)$ & urine \\
\hline
\end{tabular}

Table(2): Total number of bacterial isolates.

\begin{tabular}{|l|c|}
\hline Bacterial isolates & No. of isolates \\
\hline E. coli & $148(51.7 \%)$ \\
\hline Klebseilla spp. & $37(12.9 \%)$ \\
\hline Pseudomonas aeruginosa & $16(5.5 \%)$ \\
\hline Staphylococcus aureus & $15(5.2 \%)$ \\
\hline Proteus spp. & $14(4.8 \%)$ \\
\hline Staphylococcus hemolyticus & $8(2.7 \%)$ \\
\hline Staphylococcus hominis & $5(1.7 \%)$ \\
\hline Staphylococcus saprophyticus & $5(1.7 \%)$ \\
\hline Staphylococcus lentus & $3(1.04 \%)$ \\
\hline Staphylococcus xylosus & $3(1.04 \%)$ \\
\hline Staphylococcus epidermidis & $3(1.04 \%)$ \\
\hline Enterococcus faecalis & $3(1.04 \%)$ \\
\hline Uncommon bacterial species & $23(9.8 \%)$ \\
\hline Unidentified bacterial isolates & $3(1.04 \%)$ \\
\hline Total isolates & 288 \\
\hline
\end{tabular}

In a study in Switzerland by Gayral et al., (1997), they were evaluated Vitek 2 system for rapid identification of the 845 strains medically relevant gram negative rod. Only $7(0.8 \%)$ strains were misidentified, and $10(1.2 \%)$ were not identified. Thus its database was challenged by a diverse group of organisms, including species which are very rarely encountered in the routine clinical laboratory.

This result is near to a study by Rit $e$ al., (2013) they were isolated one strain of $P$. stutzeri from urine sample when collected 201 different isolates of nonfermentor gram negative from 
various clinical sample. Also in a study in USA by Helio et al.,(2005) they were isolated $O$. anthropi, S.paucimobilis, P. stutzeri, P. fluorescens/P. putida and Aeromonas spp.: 0.8, 0.8, 1.1, 7.2 and 11.0 in different clinical samples, respectively when they collected 3059 strains of nonenteric gram negative bacilli as part of the Sentry Antimicrobial Surveillance Program during (1997-2003).

Studies concerning the prevalence of A. otitis in otitis medea have been performed only in Finland (Hendolin et al., 1997 and Leskinen et al., 2002) and in the United Kingdom (Beswick et al., 1999). Other than in these two countries, only a few clinical strains of A. otitis have been isolated in the United States (Faden and Dryja. 1989), Turkey (Kalcioglu et al., 2002), Spain (Gomez-Hernando et al., 1999), and Brazil (Sih et al., 1992). In Asian countries, even the isolation of A. otitis has not been reported yet.

All isolates were growth on MacConky's plate considered as gram negative rods with observed by gram staining which is mentioned by Forbes et al., (2007), in addition to the ability of lactose fermenting. Oxidase and IMViC test were the best separation for differentiation infrequent gram negative bacterial species from common species. as well as the bacterial growth on blood agar and nutrient agar or one of them without growth on MacConky's agar were considered as gram positive cocci by gram staining which is also mentioned by Forbes et al., (2007), in addition to the ability of hemolysis. Catalase test and growth on Manitol sult agar after subculturing were the best separation between Staphylococci and Streptococci. All reactions were recorded daily, with final readings at $72 \mathrm{hr}$. No changes in reactions were observed past $72 \mathrm{hr}$.

The production of methyl red and citrate utilizing were the strong parameter for identifying as Citrobacter spp. in addition to the ability to lactose fermenting which was pink in $C$. freundii as the same reaction in E. coli, whereas it was weaken in C. koseri. There are many studies that have been conducted on citrobacter by Raof et al., (2013) in Tikrit, that they are disagree with present result because they were depended on routine identification which is not efficient to citrobacter identification. Whereas there are many studies near to present result by Al-Hissnaway et al., (2010) in Iraq and (Shahid 2010) in india.

The colonies characteristic of Acinetobacter calcoaceticus and Acinetobacter baumanii were as follows: On MacConkey's agar the colonies were pale and non-lactose fermenting. The result of 
gram staining showed gram negative coccobacilli it is important characteristic with negatively oxidase in routine identification.

In a multicentre study by the Centers of Disease Control(CDC), Atlanta, Georgia, over a period of four years A. calcoaceticus was the causative organism in 1372 of 180982 cases of infections reported to the center (Gajaylife 1984). Kaplan et al., (1984) reported a case of postoperative urinary tract infection and also attempted the detection of humeral antibody against the organism.

The characteristics of $S$. paucimobilis was gram negative bacilli and had yellow-pigmented and nonmucoid colonies on nutrient agar plates that were positive. Colonies on MacConky's were non-fermented lactose. Kilic et al., (2007 concluded that $S$. paucimobilis strains can cause outbreaks in hemato/oncology units. They did not demonstrate genetic relatedness between clinical and environmental isolates by pulsed-field gel electrophoresis (PFGE).

The characteristics of Ochrobactrum anthropi, colonies were as follows: On nutrient agar, there were small size, circular, low convex, smooth, shining with entire margin, and nonhemolytic colonies on blood agar. Non lactose fermenting isolate was obtained after overnight incubation on MacConkey's agar.

Theodore et al., (1992), who described the first patient infected by $O$. anthropi in a child, that of bacteremia in a 3-year-old girl undergoing chemotherapy for retinoblastoma. also they absorbed that O. anthropi closely related bacterial species, namely Alcaligenes xylosoxidans subspecies xylosoxidans, Agrobacterium radiobacter, and "Achromobacter" group B.

The colony morphology of $M$. morganii isolates on MacConkey agar appears large, smooth, convex, and translucent as well as it was non lactose fermenting, also it was a gram negative coccobacilli in gram staining smear.

This study were near to local study in Bagdad by Auda J. Gh. and Al-Grawi (2009) who was isolated two strain form 220 urine sample during two years and with global by Friedman et al., 2015 in Tel Aviv who isolated one strain of M. morganii from 257 children initially diagnosed with UTI. While there were studies recognized most commonly in hospitalized with indwelling urinary catheters and in surgical (Gates et al., 1986).

The colonies characteristic of A. salmonicida were circular, entire, raised, glistening, cream colored on nutrient agar and odor producing. No pigment was produced at either $22^{\circ} \mathrm{C}$ or $37^{\circ} \mathrm{C}$ 
after growth for 1 week. Gram staining appeared some description about size and shape, this phenomenon maybe the first time in this species.

A. salmonicida is considered to be nonpathogenic for humans as it cannot grow at $37^{\circ} \mathrm{C}$. "However, In our laboratory culture plates and broths were incubated twice at $37^{\circ} \mathrm{C}$ and each time the same types of colonies were isolated which were identified as A. samonicida by Vitek 2 compact system. Based on the previous studies, A. salmonicida that non pigmented and will able growth at $37^{\circ} \mathrm{C}$ was atypical strain and the reliability of using pigment production in diagnosing typical A. salmonicida has also previously been questioned (Austin \& Austin 1987).

E. ludwigii was identified based on Vitek 2 (BioMerieux, France) it was very good identification as confidence, in spite of Vitek 2 can be separated their result to related species. $E$. ludwigii was the accurate species up on separated tests that suggested from the Vitek report.

In a Doctoral study in Nottingham by Abdulla (2014) who isolated one strain of E. ludwidgii from neonatal meningitis when she was identified by 16S rRNA. also Hoffmann et al., (2005) conducted E. ludwigii strain belongs to the E. cloacae complex was first reported and nominated in 2005 and later been found in many hospitals.

P. fluorescens was isolated from sputum in a patient suspected with tuberculosis. The growth appeared after 48 hours with mucoid colonies. This mucoidly may be due to pigment production that was yellow-green fluorescent as shown in below figure.

Colonies of $P$. stutzeri on nutrient agar were dry, coherent, ridged (rough)with concentric spreading areas and non-pigmented as shown in below figure. They were gram negative rod which was seen in single arrangement. Both strains grew as non-lactose fermenting colonies on MacConkey's agar. Fresh colony that was picked off from nutrient agar gave positive reaction for oxidase.

In a local study in Thi-Qar by Abas et al., (2014) on detection on multidrug resistant of Pseudomonas spp., isolated one strain of P. fluorescens from wound swab when collected 210 clinical sample. Although in a study by Shrooq et al., (2014) in Bagdad city on the ability of $P$. fluorescens to produce bacteriocin when they observed inhibition of some gram negative and positive. 

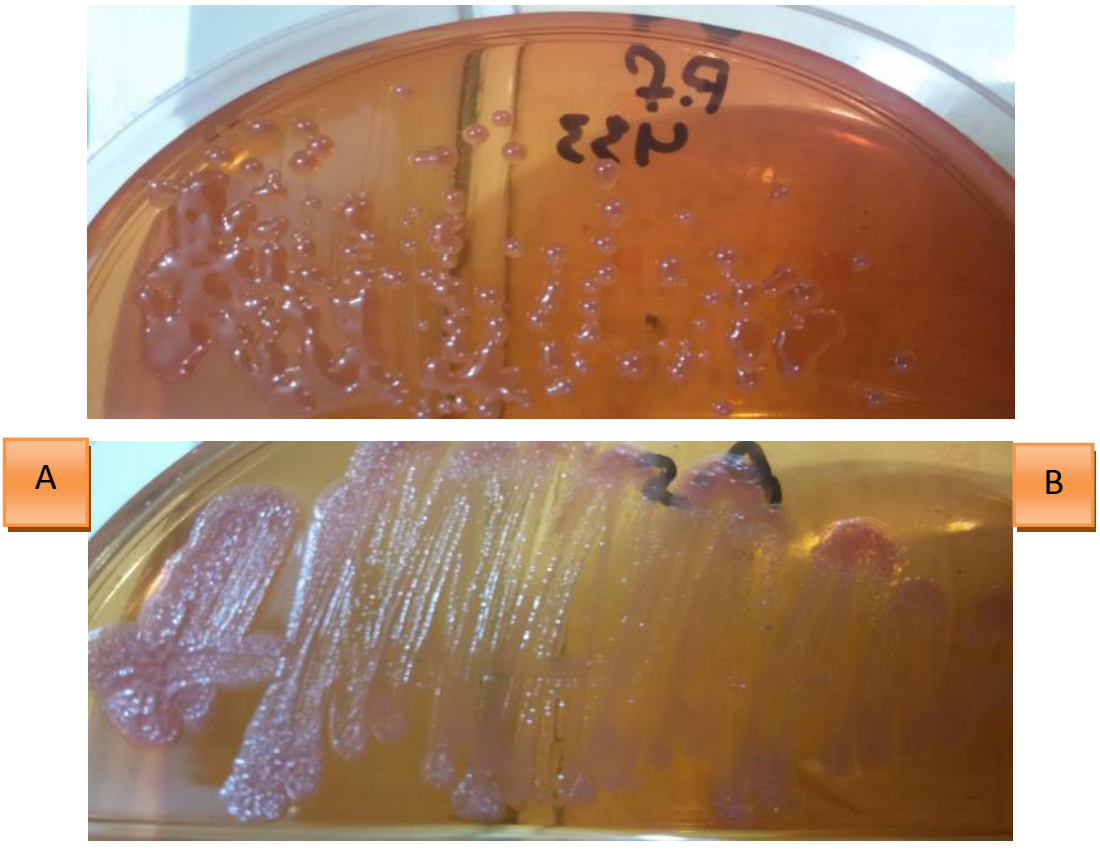

Figure: A. Showing mucoid colonies of P. fluorescens on MacConkey agar; B. Showing dry colonies of P. stutzeri on MacConkey's agar.

There are two main types of colony of $P$. stutzeri observed on nutrient agar by Lapagel (1968), they described the first type as the same our type (rough) and the second type, they described as a mucoid colony (" smooth "). Whereas study of Stanier et al., (1966) they were founded both colony forms (Rough and smooth) when isolated from human sources.

The colonies of M. luteus were convex, smooth, and yellowish on blood and nutrient agar. The organism was positive for catalase and oxidase, as well as it produced yellow pigment that was considered as identification criteria. Arrangementwere tetrad in the gram staining and the confidence identification Vitek was excellent.

Peces et al., 1997 concluded that M. luteus should be considered as an emerging nosocomial pathogen in immunocompromized patients. Persistent bacteraemia unresponsive to medical management should be treated by catheter removal.

Colonies of $K$. rosea were circular, slightly convex, smooth (occasionally rough) on nutrient and blood agar. Colony morphology and color become more distinct with age. Bacterial cells were spherical and occurred in pairs, tetrads, and clusters. All biochemical tests in urine strain were negative only POLYB was positive in the Vitek biochemical profile and the probability identification was $89 \%$. But we observed only two enzymes in the biochemical profile in blood strain; also the probability was $94 \%$. 
K. kristinae was grown on blood agar and nutrient agar, whereas no growth was observed on McConkey's agar. Gram staining of the colonies revealed the presence of gram positive cocci which were mostly arranged in tetrads. The organism which was catalase positive. They possesses positive reaction for some sugar such as glucose (AGLU), maltose (dMAL), (SAC), (LAC), and optochin (OPTO) in the Vitek biochemical profile and the probability identification was $89 \%$. These distinctive characteristics were unique in this strain among micrococci which means it is able to utilize these sugars as well as that is able to ferment lactose, in addition to resist against optochin antibiotic.

In the recent reported cases by Tewari et al., (2013) of K. kristinae in urinary tract infection in a catheterized, 20-years old male that was considered as the first reported case of a catheter related urinary tract infection which was caused by $K$. kristinae. In another report in India by Lakshmikantha et al., (2015) they isolated K. kristinae from urine and blood samples.

We believe that a reliable identification of Kocuria spp. is possible with the use of the Vitek 2 GP card. Since these isolates are rare in the routine microbiology laboratory. A better understanding of the potential pathogenicity of this species will be more apparent after the report of more cases and possess ingredients of resistance to antibiotics.

The growth of A. urinae was observed on blood agar and nutrient agar with appeared $\alpha$ hemolytic and small colonies. As well as the gram staining showed single cell, diplococci, streptococci and tetrad in arrangement. A negative catalase reaction and positive reaction of optochin was showed in Vitek result and the probability was $89 \%$.

A. urinae, previously known as Aerococcus-like organism, is an uncommon pathogen. Previous reports from European countries indicate that it is associated with UTI (Christensen et al., 1991), bacteremia (Christensen et al., 1995).

Our result of the isolation of A. urinae was near to that of a study in USA by Sierra-Hoffman et al., (2005) that revealed the rate of A. urinae recovery $0.25 \%$ in the study period during (20012002) who receives from microbiology laboratory approximately 30000 specimens per year for urine culture.

The isolation of A. otitis in urine sample was a first time and was grown slowly on blood and nutrient agar, Only PyrA and dTRE were positive reaction in biochemical Vitek profile and the probability was $93 \%$. It has been recovered from the middle ear of children with acute otitis 
media, studies showed that A. otitis was frequently found in the outer ear canals of healthy volunteers (Frank et al., 2003). It is very difficult to culture. So far, only a few clinical strains of A. otitis has been isolated (Faden and Dryja 1989). However, previous studies by Hendolin et al., (1997) showed that $A$. otitis was never detected by culture, but it was detected by PCR more frequently than other middle ear pathogens.

Colonies Of $G$. sanguinis were grown on blood agar plates after 48 hour of incubation. The colonies after 24 hours appeared small, circular, entire, translucent, smooth, and non-pigmented. Catalase and oxidase reaction were negative. According to the Vitek biochemical profile, only three reactions were positive among 43 tests, namely; APPA, OPTO and PHOS. Although the probability identification was $97 \%$.

This result is near to a study by Ma et al., (2015) they observed the colonial growth on blood agar after $48 \mathrm{hr}$. of incubation, which showed non-hemolytic, tiny, pinpoint, smooth, translucent to grayish colonies. Gram stain showed gram-positive cocci in pairs. Also it was identified as G. sanguinis by Vitek 2-Compact System (Biomerieux, France).

We have been found that A. calcoaceticus, A. baumanii, and E. ludwigii were resistant to all antibiotics. Whereas $C$. freundii isolates were resistant to twenty two antibiotics $91.6 \%$, and it was sensitive for Meropenem and Doripenem.

Alsough S. paucimobilis, M. morganii and P. agglomerans were resistant to twenty one antibiotics $87.5 \%$, but they were sensitive for (Meropenem and Doripenem and Pepracilln), (Meropenem, Levofloxacin and Ciprofloxacin) and (Meropenem, Cefexim and Netilmicin), respectively.

O. anthropi (n.1) was resistant to twenty antibiotics 83.3\%, and it was sensitive for Meropenem, Doripenem, Levofloxacin and Ciproflxacin but another strain (n.2) was resistant to nineteen antibiotics $79.1 \%$, and it was sensitive for Meropenem, Doripenem, Levofloxacin and Ciproflxacin in addition to Doxicycline.

Although $C$. koseri, $P$. stutzeri(n.1and n.2) and $P$. fiuorescens were resistant to seventeen antibiotics 66.6\%, whereas they were sensitive for Meropenem, Doripenem, Levofloxacin and Ciproflxacin, in addition to Tobramicin, Amicacin and Netilmicin, but the second strain of $P$. stutzeri(n.2) was sensitive to the same antibiotics except Cefepem instead of Amikacin. 
Finally, A. salmonicidis as the more sensitive strain among gram negative that were resistant to the sixteen antibiotics 62.5\%, and it was sensitive for Meropenem, Doripenem, Azteronam, Cefepem, Ciproflxacin, Doxycycline, Tetracycline and Nitrofurantion.

In the light of above results, all of these bacterial species, possess ingredients of resistance in different degrees because each bacterial species possesses enzyme or some enzymes, structure or more and intrinsic resistance.

A. baumanii, A. calcoaceticus and E. ludwigii have possessed all ingredients of resistance, that are acquired in the host when exposed to drugs and host immune system or possessed normally. Whereas $C$. freundii has possessed all ingredients of resistance except to one group of $\beta$-lactam that is carbapenem which inhibits activity of bacterial enzymes that is essential for peptidoglycan synthesis (penicillin binding proteins), in addition to inhibition by carbapenem it was inhibited by Tetracycline that's tetracyclines group which inhibits protein synthesis (Kiser et al., 2011).

Also $S$. paucimobilis was inhibited by carbapenem group and Piperacillin that is penicillin group of $\beta$-lactam which is the same action of carbaenem but $M$. morganii was inhibited by carbapenem group and Ciprofloxacin that is fluoroquinolones group which inhibits DNA gyrase in gram negative bacteria. (Kiser et al., 2011).

Both strains of $O$. anthropi have been inhibited by carbapenem and fluoroquinolones group but the second strain has been inhibited by carbapenem and fluoroquinolones in addition to Doxicycline that's tetracyclines group. They are bacteriostatic and so are used less often because of the bactericidal effect of the $\beta$-lactams. (Kiser et al., 2011).

Although C. koseri, P. stutzeri (n.1) and P. fluprescens has been inhibited by carbapenem and fluoroquinolones in addition to Tobramycin, Netilmycin and Amikacin that are aminoglycosides which is preventing translation of mRNA during binds to the $30 \mathrm{~S}$ ribosomal subunit (Kiser et al., 2011), also another strain of P. stutzeri (n.2) was susceptible to the same antibiotics in addition to Cefepem which is fourth generation of cephalosporins and acts as natural penicillins.

Whereas A. salmonicida was susceptible to a wide range of antibiotics, some of them $\beta$ lactams such as, carbapenem, Cefepem, Azteronam which act as natural penicillins, and others such as, aminoglycoside, tetracyclines, Ciprofloxacin and Nitrofurantion act on damaging bacterial DNA . Macrobid Drug Label FDA. Retrieved 21 April 2014 
Only one gram positive isolates that was resistant to all antibiotics or possessed all ingredients of resistance as we discussed in susceptibility in gram negative. However, that gram positive may be more resistance due to its possession the thick cell wall which protects the cell from toxic substances. G. sanguinis was resistant to all antibiotics, whereas Aerococcus urinae was resistant to twenty three antibiotics $(95.8 \%)$ expect Nitrofurantion that acts on damaging DNA. Also All. otitis was resistant to twenty two antibiotics $91.6 \%$, and it was sensitive for Nitrofurantion and Netilmycin as well as that S. sobrinus was resistant to twenty one antibiotics $87.5 \%$, and sensitive for Meropenem, Pepracillin and Nitrofurantion.

Whereas Micrococcuceae have less resistance, when $K$. kristinae was resistant to twenty antibiotics $83.3 \%$, and susceptible to $\beta$-lactam; carbapenem group, Cefadroxil and Cefazolin that are the first generation of cephalosporins which are act as natural penicillins (Kiser et al., 2011).

Both strains of $K$. rosea are different to susceptibility. $K$. rosea (n.2) was isolated from urine sample that was more resistance than the another strain, then each of $K$. rosea (n.2) and $S$. sobrinus were resistant to twenty one antibiotics $87.5 \%$, whereas $K$. rosea (n.2) was sensitive for Pipracillin, Ampicillin and Nitrofurantion, also S. sobrinus was sensitive for each Pipracillin, Meropenem and Nitrofurantion. But another strain of $K$. rosea(n.1) that isolated from blood sample was resistant to nineteen antibiotics $79.1 \%$, and it was susceptible to carbapenem group, fluoroquinolones and Tetracycline.

Either M. luteus, both strains are more sensitive to a wide range of antibiotics in composition to others. M. luteus (n.1) was resistant to sixteen antibiotics $66.6 \%$, and it was susceptible to the followings; carbapenem group, Pepracillin, Cefazolin, cefepem, fluoroquinolones and tetracyclines. Whereas another strain (n.2) was resistant to fifteen antibiotics $62.5 \%$, and it was susceptible to the followings; carbapenem group, Pepracillin, Cefazolin, Ampicillin, Ceftriaxone, Ciprofloxacin, Netilmicin and tetracyclines.

That was a report on 219 strains of Kocuria and Micrococcus showed that the majority of strains were sensitive to doxycycline, ceftriaxone, cefuroxime, amikacin, and amoxicillin with clavulanic acid, but resistant to ampicillin and erythromycin (Szczerba 2003).

The high sensitivity of $M$. luteus to $\beta$-lactam antibiotics may result from the presence of a reduced set of penicillin-binding proteins and the absence of a wblC gene, which plays an important role in the antibiotic resistance in other actinobacteria( Young et al., 2010). 


\section{References}

Abas Y.A., Khudaier and Salih Y.A. 2014. Detection of Multidrug Resistant Pseudomonas spp. in Clinical Cases and Hospital Environments at Thi-Qar Province. Journal of College of Education for Pure Sciences Vol. 4

Abdulla H. 2014. Neonatal enteral feeding tube as loci for Enterobacteriaceae colonisation and risk to neonatal health. A thesis of Doctor of Philosophy /Nottingham Trent University.

Al-Hissnawy D.S., AL-Thahab A.A. and Al-Jubori S.A. 2010. Evaluation of Citrobacter freundii isolated in Najaf governorate as an enterotoxin producer. College of Dentistry/Kufa University.

Auda J. Gh. and Al-Grawi I. Gh. 2009. Isolation, Identification, and Antimicrobial Susceptibility of Uropathogenic Morganella Morganii Al- Kindy Col Med J; Vol .5 (1) P:32-35.

Ausubel F.M., Brent R., Kingston R.E., Moore D.D., Smith J.A., Seidman J.D. and Struhl K. 1987. Curren Protocol in Molecular Biology. Jhon Wiley and Sons. Inc, NewYork.

Austin B., Austin D. A. 1987. Bacterial fish pathogens: Disease in farmed and wld fish. EUis Honvood Limited, Chichester, p. 11 1-195.

Bhatia R., Tomar J. 2016. Sphingomonas paucimobilis - an emerging pathogen. Int J Contemp Pediatr. 3(3):1123-1125.

Bodey G. P., Elting L., Kassamali H. and Lim B. 1986. Escherichia coli bacteremia in cancer patients. Am. J. Med. 81(Suppl. 1A):85-95.

Bodey G. P., Elting L., Rodriguez S. and Hernandez M. 1989. Klebsiella bacteremia: a 10-year review in a cancer institution. Cancer 64:170-178.

Bodey G. P., and Jadeja J. 1985. Pseudomonas bacteremia: retrospective analysis of 410 episodes. Arch. Intern. Med. 145:1621-1629.

Chen H., Chi H. Chiu N. and Huang F. 2015. Kocuria kristinae: A true pathogen in pediatric patients. Journal of Microbiology, Immunology and Infection 48, 80e84. Polish.

Christensen J. J., and Gutschik E. 1991. Urosepticemia and fatal endocarditis caused by Aerococcus-like organisms. Scand. J. Infect. Dis. 23:717-721. 
Christensen J.J., Jensen I.P., Faerk J., Kristensen B., Skov R., Korner B. 1995. Bacteremia/septicemia due to Aerococcus-like organisms: report of seventeen cases. Danish ALO Study Group. Clin Infect Dis 1995; 21: 943-947.

Faden H., and Dryja D. 1989. Recovery of a unique bacterial organism in human middle ear fluid and its possible role in chronic otitis media. J. Clin. Microbiol. 27:2488-2491.

Folland D., Armstrong D, and Seides S. 1974. Pneumococcal bacteremia in patients with neoplastic disease. Cancer 33:845-849.

Forbes B.A., Sahm D.F. and Weissfeld A.S. (2007). Bailey \& Scott's Diagnostic Microbiology. $12^{\text {th }}$ ed. Mosby, Inc., an Affiliate of Elsevier Inc.

Frank D.N., Spiegelman G.B., Davis W., Wagner E., Lyons E. and Pace N.R. 2003. Cultureindependent molecular analysis of microbial constituents of the healthy human outer ear. J Clin Microbiol 41:295-303.

Friedman S., Reif S., Assia A., Levy I. 2015. Clinical and laboratory characteristics of non-E coli urinary tract infections. http://adc.bmj.com/ Published by group.bmj.com.

Gajaylife B. D. 1984. Serotyping of Acinetobacter calcoaceticus. J Clin Pathol 37:1388-1391.

Gates M.L., Sanders C.C., Goering R.V., Sanders W.E. 1986. Evidence of multiple forms of type I chromosomal beta-lactamase in Pseudornonas aeruginosa. Antimicrobial Agents and Chemotherapy, 30: 453- 457.3

Gomez-Hernando C., Toro C., Gutierrez M., Enriquez A., and M. Baquero. 1999. Isolation of Alloiococcus otitidis from the external ear in children. Eur. J. Clin. Microbiol. Infect. Dis. 18:6970.

Gayral J. P., Robinson R., and Sandstedt D. 1997. A new integrated system for microbiological testing: the Vitek II system, abstr. P254. Clin. Microbiol. Infect. 3(Suppl. 2):53.

Guttman D. S., Morgan, R. L. and Wang, P. W. 2008. The evolution of the Pseudomonads, In: M. Fatmi, A. Collmer, N. S. Iacobellis, J. W. Mansfield, J. Murillo, N. W. Schaad, and M. Ullrich (eds) Pseudomonas syringae Pathovars and Related Pathogens, 307-20, Springer, Netherlands. 
Helio S.,Sadera b., Ronald N and Jonesa c. 2005. Review; Antimicrobial susceptibility of uncommonly isolated non-enteric Gram negative bacilli. International Journal of Antimicrobial Agents 25, 95-109.

Hendolin P. H., Markkanen A., Ylikoski J., and Wahlfors J. J. 1997. Use ofmultiplex PCR for simultaneous detection of four bacterial species in middleear effusions. J. Clin. Microbiol. $35: 2854-2858$.

Hoffmann H., Stindl S., Stumpf. A., Mehlen A., Monget D., Heesemann J., et al. 2005. Description of Enterobacter ludwigii sp. Nov., a novel Enterobacter species of clinical relevance. Systematic and Applied Microbiology, 28, 206-212.

Jossart, M. F., and Courcol R.J. 1999. Evaluation of an automated system for identification of Enterobacteriaceae and nonfermenting bacilli. Eur. J. Clin. Microbiol. Infect. Dis. 18:902-907.

Kalcioglu M. T., Oncel S., Durmaz R., Otlu B., Miman M.C., and Ozturan O. 2002. Bacterial etiology of otitis media with effusion; focusing on the high positivity of Alloiococcus otitidis. New Microbiol. 25:31-35.

Kaplan J. B., Anita P. J. and Nichols B. P. 1984. Nucleotide Sequence of the Acinetobacter calcoaceticus trpGDC Gene Cluster. WALTER M. FITCH, reviewing editor.

Kilic A., Senses Z., Kurekci A.E., Aydogan H., Sener K., Kismet E., et al. 2007. Nosocomial outbreak of Sphingomonas paucimobilis bacteremia in a hemato/oncology unit. Jpn J Infect Dis 60:394-6.

Kiser K.M., Payne W.C. and Taff T.A. 2011. Clinical Laboratory Microbiology A Practical Approach. Pearson education, Inc., New Jersey.

Lakshmikantha M., Devki V. and Yogesh C. 2015. Is Kocuria kristinae an upcoming pathogen?. Int.J.Curr.Microbiol.App.Sci 4(4): 885-889.

Lapagel S.P.,. 1968. Hill R. Reeve J. Pseudomonas stutzeri i n pathological material. J. MID. Microbi01.-vol. 1

Leskinen K., Hendolin P., Virolainen-Julkunen A., Ylikoski J. and Jero J. 2002. The clinical role of Alloiococcus otitidis in otitis media with effusion. Int J Pediatr Otorhinolyngol 66:41-8. 
Levinson W. 2010. Review of Medical Microbiology and Immunology. $11^{\text {th }}$ ed. McGraw-Hill companies. New York.

Ma M., Bhalla L. S., Shete V., Grover C.N. 2015. Gemella sanguinis: A rare cause of native valve endocarditis in a child. Medical Journal med forces India a. 628; No. of Pages 3.

Pal R.B., Kale V.V. 1981. Acinatobacter calcoaceticus an oportunistic pathogenic. Vol. 27 Issue : $4: 218-21$.

Peces R., Gago E., Tejada F., Laures A.S. and Alvarez-Grande J. 1997. Relapsing bacteraemia due to Micrococcus luteus in a haemodialysis patient with Perm-Cath catheter. Nephrol Dial Transplant 12:2428-2429.

Raoof W.M., Ali K.O. and Mohammed S.A. 2013. Study The Resistance of some Bacteria at the Most Commonoly Isolated from Tikrit Teaching Hospital Infections to Antibiotics and their Relation with Plasmids.Tikrit university/Iraq.

Rit k., Nag F., Raj H.J. and Maity P.K. 2013. Prevalence and Susceptibility Profiles of Nonfermentative Gram-negative Bacilli Infection in a Tertiary Care Hospital of Eastern India. Indian Journal of Clinical Practice, Vol. 24, No. 5.

Robert C. N. and Overman S.B. 1994. Pseudomonas stutzeri Infection A Review of Hospital Isolates and a Review of the Literature. DIAGN MICROBIOL INFECT DIS 51;19:51-56.

Shahid M. 2010. Citrobacter spp. Simultaneously Harboring blaCTX-M, blaTEM, blaSHV, blaampC, and Insertion Sequences IS26 and orf513: an Evolutionary Phenomenon of Recent Concern for Antibiotic Resistance. Journal of clinical microbiology, p. 1833-1838 Vol. 48, No 5.

Shrooq R.K., Kifah A.J. and Mayssaa, E.A. 2014. The antimicrobial activity of bacteriocin from pseudomonas fluorescens against pathogenic bacteria . Basrah Journal of Science (B) Vol. 32(2), 206-213

Sierra-Hoffman M, Watkins K, Jinadatha C, Fader R, Carpenter JL. Clinical significance of Aerococcus urinae: a retrospective review. Diagn Microbiol Infect Dis 2005; 53: 289-292.

Sih, T., B. Schwartz, G. Bosley, and R. Facklam. 1992. Chronic otitis media effusion caused by Alloiococcus otitis: clinical and laboratory features, abstr. 671, p. 222. In Program and abstracts 
of the 32nd Interscience Conference on Antimicrobial Agents and Chemotherapy. American Society for Microbiology, Washington, D.C.

Stanier R. Y., Palleroni N.J. and Doudoroff M. 1966. The aerobic Pseudomonas: a taxonomic study. J. Gen. Microbiol. 43:159.

Szczerba I. 2003. Susceptibility to antibiotics of bacteria from genera Micrococcus, Kocuria, Nesternkonia, Kytococcus and Dermacoccus. Med Dosw Mikrobiol. 55:75-80.

Tewari R., Dudeja M., Das A.K. and Nandy S. 2013. Kucuriae kristinae in catheter asociated urinary tract infection: a case report. Journal of Clinical and Diagnostic Research. Vol-7(8): 1692-1693.

Theodore J. C., Drabick C. J., Fisher G.W. and Robb M. L.1992. Catheter-Associated Sepsis Caused by Ochrobactrum anthropi: Report of a Caseand Review of Related Nonfermentative Bacteria. http://cid.oxfordjournals.org/ at University of Manitoba

Vandepitte J., Verhaegen J., Engbaek K., Rohner P., Piot P. and Heuck C.C. 2003. Basic laboratory procedures in clinical bacteriology. WHO. Geneva.

Weinstein M.P., Towns M.L., Quartey S.M., et al. 1997. The clinical significance of positive blood culture in the 1990s: a prospective comprehensive evaluation of the microbiology, epidemiology and outcome of bacteremia and fungemia in adults. Clin. Infect. Dis. 24:584-602.

Young M., Artsatbanov V., Beller H.R. et al. 2010. Genome Sequence of the Fleming Strain of Micrococcus luteus, a Simple Free-Living Actinobacterium. Journal of bacteriology, p. 841-860. 